\title{
Music Stimulation as a Method of Optimizing Autobiographical Memory in Patients Diagnosed with Alzheimer's Disease
}

\author{
Ariana Ponce-Pardo ${ }^{1}$, Pamela Acosta-Rodas ${ }^{1}$, Jorge Cruz-Cárdenas ${ }^{2}$, \\ Carlos Ramos-Galarza ${ }^{1,3^{*}}$ \\ ${ }^{1}$ Facultad de Psicología, Pontificia Universidad Católica del Ecuador, Av. 12 de Octubre y Roca, Quito, Ecuador \\ ${ }^{2}$ Research Center in Business, Society, and Technology, ESTec, Universidad Tecnológica Indoamérica, Quito, Ecuador \\ ${ }^{3}$ Centro de Investigación en Mecatrónica y Sistemas Interactivos, Universidad Indoamérica. Machala y Sabanilla, Quito, Ecuador
}

\begin{abstract}
Alzheimer's is a neurodegenerative disease characterized by the progressive deterioration of cognitive functions, with memory being the most affected. Several studies have shown the benefits of music as a complementary treatment for dementia, improving patients' quality of life. A scientific contribution is needed to show how autobiographic memory could be improved by using musical activities. Objective: The aim of this investigation is to analyze the impact of a musical stimulation protocol on the performance of autobiographical memory in elderly people suffering from Alzheimer's. Participants and Method: This research was conducted with three patients diagnosed with Alzheimer's disease: two females (66.7\%), and one male (33.3\%). One (33.3\%) was in the early stages, and two were in the middle stages. This investigation used a quantitative, pre-experimental, longitudinal study with the application of two tests before and after the intervention. Findings: Changes in the performance of autobiographical memory $(\mathrm{t}=-5.79$, $\mathrm{p}=0.002)$, and in the semantic component $(\mathrm{t}=-10.14, \mathrm{p}=0.01)$ were found to be statistically significant, but no changes were evident for episodic memory $(\mathrm{t}=-0.19, \mathrm{p}=0.86)$. Conclusion: This study provides preliminary evidence of the potential effectiveness of using a music protocol to improve the performance of autobiographical memory in patients with Alzheimer's Disease.
\end{abstract}

\section{Keywords:}

Alzheimer's Disease;

Autobiographical Memory;

Music; Stimulation Protocol;

Older Adults.

\section{Article History:}

Received: 16 June 2021

Revised: $\quad 08 \quad$ September 2021

Accepted: $\quad 19$ September 2021

Published: $01 \quad$ October 2021

\section{1- Introduction}

Dementia is a neurodegenerative disease that, according to Alzheimer's Disease International [1], affects approximately 9.9 million people worldwide each year. This implies that every three seconds, a person is diagnosed with any type of dementia. It is estimated that in 2050, 131.5 million people will suffer from this pathology. Alzheimer's Disease (AD) is the most known type of dementia, accounting for 60-70\% of total cases [2]. It is characterized by the progressive and irreversible impairment of cognitive functions, and neuropsychological alterations such as aphasia, apraxia, agnosia, and significant memory impairment. It often comes with behavior and mood swings, and progresses toward total dependency [3]. The etiology of AD is characterized by the accumulation of beta-amyloid peptides and tau proteins in the brain, which generate plaques and neurofibrillary tangles, resulting in the extensive loss of neuronal synapses and cognitive impairments [4]. In the early stages, the damage is located in the temporal lobe, commonly in the hypothalamus zone, and progresses and extends into the whole brain [5]. Memory loss is the most common symptom

*CONTACT: caramos@puce.edu.ec

DOI: http://dx.doi.org/10.28991/esj-2021-01304

(C) 2021 by the authors. Licensee ESJ, Italy. This is an open access article under the terms and conditions of the Creative Commons Attribution (CC-BY) license (https://creativecommons.org/licenses/by/4.0/). 
and the principal motivation for relatives or patients themselves to look for medical assistance. In the course of the illness, memory and its subsystems, such as explicit, implicit, and working memory, suffer impairments or a significant diminishing in their functioning through the different stages of the disease [6].

Autobiographical memory (AM) is a type of memory based on the model of episodic and semantic memory [7]. It is composed of different levels of specification: life milestones, which are a general acknowledgment of important events; general events, which represent events that are characterized by reaching an objective that transmits meaningful information about the self; and specific event knowledge, which encompasses a high level of details specificity. AM is fundamental for meaningfulness of self, the emotions and experiences that compose personality [8]. This explains why, when AM is impaired in older adults with Alzheimer's disease, there is a decrease in their sense of identity. When encountering difficulties in recovering and evoking their own life information, this component is considered necessary for emotional being and quality of life [9]. Several studies have focused on alternative treatments to improve the lives of older adults suffering from Alzheimer's disease, since pharmacological treatment carries secondary effects, and is not highly effective in diminishing the progression of symptomatology. A research line of central interest in AD is related to cognitive, emotional, and motor aspects through the usage of music as a therapeutic method, aiming to improve the quality of life of these patients. This topic is still a new developing field, yet studies conducted have shown positive results in decreasing neuropsychiatric symptoms $[10,11]$.

Some theorists have investigated music effects in Alzheimer's disease and determined that the brain region where music memory is located is significantly less damaged than other regions, and may depend on different memory systems and be related to different tasks [12]. Different from the other cognitive functions, musical abilities (answering, evoking, or reproducing music through singing, composition, or instrumental manipulation) are preserved, even in the late stages of the disease [13]. Hence, it has therapeutic benefits that activate neuronal processes and benefit cognitive, motor, psychosocial, and behavioral functions [14]. It has been determined that responding to musical stimuli at different stages of $\mathrm{AD}$ is more efficient than responding to touch or objects [15]. Music is a predominant effective stimulus to evoke autobiographic memories [13], together with associated emotions, and is capable of strengthening a sense of identity [5]. This effect has been observed in healthy individuals, and is known as music-evoked autobiographical memories (MEAMs) [16]. People with AD are able to evoke MEAMs while listening to their preferred music and show ease in recognizing it; they are able to regain information immediately with higher emotional content, identify themselves, and use more complex language [17]. At the same time, it has been shown that music therapy works as an effective tool to support verbal memory in people suffering from AD instead of solely using speech [13]. Specifically, Fraile et al. [18] suggested that $\mathrm{AD}$ patients are able to learn songs, demonstrating that they still have the capacity to learn new information. Finally, due to their evocative power, songs can be used as a therapeutic tool to restore communication with relatives and caregivers [19].

Several studies have been conducted on music-based interventions that benefit people suffering from dementia, although some limitations have been identified in their methodology; for example, some studies are focused solely on the comparison of music and silence, there are practice effects due to the tasks' repetition that centers in a specific memory's modality, the study is not conducted in natural situations, there is a comparison between familiar and unfamiliar music [13], or music therapy is with other activities [20]. It is important to develop cost-effective, acceptable, and safe treatments that have the potential to improve the quality of life and reduce the symptoms of the disease, but above all, that have the capacity to be applied by family members, caregivers, and specialized places in the care of elderly people with Alzheimer's [21].

In this context, the present article sought to address this gap and find evidence of the effect of music on the performance of autobiographical memory and their semantic and episodic components through the utilization of a novel music stimulation protocol composed of: a) utilization of structured therapeutic activities based on musical stimuli; b) activities that are enjoyable but also stimulate cognitive functions; c) an innovative proposal based on previous literature that contributed positive results and novel activities in favor of memory; d) simple application of musical instruments that are easy and accessible for $\mathrm{AD}$ patients' relatives and caregivers to use and can be performed at home or in residential care facilities; and e) non-invasive activities with minimal cost.

The reader is invited to review the content of this work, which is structured primarily by the hypothesis raised, and which also served as the basis for beginning the research. A review of the method used is detailed, starting with a description of the participants who were part of the process, the instruments used for the analysis, and the musical stimulation protocol used. A description of the procedure is provided, and the results obtained are presented. Finally, the discussion of the results and their conclusions are detailed.

\section{1-1- Investigation Hypothesis}

H1: The musical intervention protocol will have a positive impact on the autobiographical memory of adults diagnosed with Alzheimer's disease. 


\section{2- Methods}

\section{2-1- Participants}

The present research was conducted in a foundation specializing in taking care of older adults diagnosed with Alzheimer's disease from Quito-Ecuador. Sampling began with a field observation of the 14 residents participating in a group activity to determine whether participants were able to follow directions. Then, a clinical observation with every pre-selected elderly patient was made to evaluate their condition and degree of cognitive impairment, taking into account the diagnostic criteria from the DSM-V and ICD-10. The inclusion criteria for participation were a diagnosis of Alzheimer's disease by a qualified physician and the ability to follow directions and answer questions easily. Exclusion criteria were any mood disorder, any degree of aggressiveness, auditory diseases that make it difficult to listen to musical stimuli, a legal representative's refusal to sign the informed consent form, or the patient not consenting to participate.

Once the described criteria were applied, three individuals were eligible for participation: two females $(66.7 \%)$ and one male (33.3\%), aged between 80 and 90 years old. Two (66.7\%) had a university degree, and one (33.3\%) had finished secondary school. All participants were divorced. Two (66.7\%) considered themselves to be mestizo, and one (33.3\%) white. Each participant was diagnosed with AD by a qualified professional three years ago (33.3\%), 10 years ago (33.3\%), and 12 years ago (33.3\%). Regarding the time of diagnosis and cognitive state of the participants, one $(33.3 \%)$ was in the early stages, and two (66.7\%) were in the middle stages. Every participant was taking pharmacological treatment and under the care of the foundation for older adults suffering from Alzheimer's disease for five months (33.3\%), nine months (33.3\%), and 15 months (33.3\%).

\section{2-2- Intervention Protocol}

The intervention protocol was designed based on the utilization of music therapy techniques, such as singing, percussion, active and passive listening, rhythm, melody, recreation, and personalized music relating to patients' experiences [22], as well as psychologically based activities that aimed to stimulate Alzheimer's patients to evoke autobiographic memories easily. Exercises were designed taking into account each patient's ludic and musical preferences and conditions. One of the main elements was using specific familiar music for each participant. To collect this information, interviews with participants' relatives were undertaken to identify favorite singers, songs, bands, instruments, genres, and time frames for music the participants once enjoyed. With the information provided by relatives, a playlist was built for each participant, with a total of 25 songs selected by the research team. Table 1 shows a short description of the intervention sessions, aiming to stimulate autobiographic memory and recuperate memories.

Table 1. Intervention Protocol.

\begin{tabular}{|c|c|c|c|}
\hline Session no. & Activity & Goal & Questions \\
\hline Session 1 & Sound exploration & $\begin{array}{l}\text { Stimulation of autobiographical memory through singing and using } \\
\text { instruments and playing "Happy Birthday," taking as reference a } \\
\text { birthday celebration, an important ritual for humans, to allow the } \\
\text { evocation of general memories and guide evocation of specific } \\
\text { memories. }\end{array}$ & $\begin{array}{l}\text { Is today your birthday? When is } \\
\text { your birthday? Which birthday has } \\
\text { been most significant for you? Why } \\
\text { did you choose this birthday? }\end{array}$ \\
\hline Session 2 & $\begin{array}{l}\text { Guess the singer or } \\
\text { song }\end{array}$ & $\begin{array}{l}\text { Use of familiar music and recognition of the singer or song to } \\
\text { recover information, beginning with general information about a } \\
\text { period of time in their life, and moving toward details of a specific } \\
\text { experience in that time. Family music is a stimulus that influences } \\
\text { emotions and memory due to its aesthetic, hedonic, } \\
\text { autobiographical, and semantic dimensions [18]. }\end{array}$ & $\begin{array}{l}\text { What song is it? Who is this singer? } \\
\text { Which period of time does this song } \\
\text { belong to? What does the era of this } \\
\text { song or singer remind you of? }\end{array}$ \\
\hline Session 3 & $\begin{array}{l}\text { Image association with } \\
\text { background music }\end{array}$ & $\begin{array}{l}\text { Activation of the autobiographical memory through the retrieval of } \\
\text { information from two components: the semantic component } \\
\text { through the memory of names, events, and concepts without } \\
\text { reference to the context of the photograph; and the retrieval of } \\
\text { information from the episodic component, related to specific events } \\
\text { associated with a specific place and time in a photograph. This may } \\
\text { be possible due to the sensory perceptual nature of music for } \\
\text { information retrieval. }\end{array}$ & $\begin{array}{l}\text { What elements can be found in the } \\
\text { photograph? Who are the people in } \\
\text { the photograph? What kind of } \\
\text { relationships do these people have } \\
\text { with you? When was this photo } \\
\text { taken? What were they doing before } \\
\text { the photo was taken? }\end{array}$ \\
\hline Session 4 & $\begin{array}{c}\text { Auditory } \\
\text { discrimination }\end{array}$ & $\begin{array}{l}\text { Identification of different sounds produced, such as sounds of } \\
\text { nature, events, and musical instruments, to inquire into the } \\
\text { memories coming from both the semantic and episodic components } \\
\text { of autobiographical memory. Sounds can be music when } \\
\text { intentionally superimposed, through listening, onto our own } \\
\text { aesthetic sub-universe [23]. }\end{array}$ & $\begin{array}{l}\text { Are you able to identify what are } \\
\text { you listening to? What does this } \\
\text { sound remind you of? }\end{array}$ \\
\hline Session 5 & Living the music & $\begin{array}{l}\text { Singing accompanied by the reading of a musical score. Since this } \\
\text { activity facilitates access to autobiographical memories, it is a } \\
\text { mechanism of self-expression that provokes feelings and collects } \\
\text { themes of a particular time to cultivate memory [24]. }\end{array}$ & $\begin{array}{l}\text { Does this song remind you of } \\
\text { something? What did you feel when } \\
\text { you heard this song? At what stage } \\
\text { of your life did you feel that way? }\end{array}$ \\
\hline
\end{tabular}




\begin{tabular}{|c|c|c|c|}
\hline Session 6 & Lyrical memorization & $\begin{array}{l}\text { Evocation of an autobiographical memory of an episodic nature } \\
\text { through the creation of a song, taking into account that learning new } \\
\text { lyrics is easier with a known melody than with an unknown one, } \\
\text { easing the memory load. Creating an associative link between } \\
\text { words and a song's lyrics that could lead to deep encoding probably } \\
\text { facilitates long-term storage and retrieval of information [18]. }\end{array}$ & $\begin{array}{l}\text { A familiar song was chosen so that } \\
\text { the participant could use the tone } \\
\text { and melody to create new lyrics for } \\
\text { that song. }\end{array}$ \\
\hline Session 7 & Creating my story & $\begin{array}{l}\text { Evocation of autobiographical memories through the use of } \\
\text { imagination to create a story that links with aspects of their own life, } \\
\text { whether periods of life, general events, or specific event details. } \\
\text { Listening to relaxing music enables verbal expression through the } \\
\text { evocation of memories or creation of images, which allows a fluid } \\
\text { therapeutic intervention, and facilitates the patient's own self- } \\
\text { knowledge [24]. }\end{array}$ & $\begin{array}{l}\text { What did you imagine? How did } \\
\text { you feel? Are you able to relate the } \\
\text { story to your own life? }\end{array}$ \\
\hline Session 8 & $\begin{array}{c}\text { Closure: Drawing my } \\
\text { past }\end{array}$ & $\begin{array}{l}\text { Evocation of autobiographical memories through musical listening } \\
\text { accompanied with drawing, taking into account that music } \\
\text { stimulates the imagination and drawing is a means of projection. } \\
\text { Generation of a space that allows them to establish adequate closure } \\
\text { of the musical protocol. "Involvement in an activity or musical } \\
\text { experience involves brain activation at different levels (...). Thus, } \\
\text { music can evoke images and memories of past experiences or } \\
\text { moments, and stimulate the creativity and imagination in a person" } \\
\text { [23]. }\end{array}$ & $\begin{array}{l}\text { What did you draw? What are the } \\
\text { memories that arise from the } \\
\text { drawings? }\end{array}$ \\
\hline
\end{tabular}

The music used for seven of the eight sessions was recorded. For each session, a sound system was located in front of the participant; the use of earphones was avoided, since in most sessions it was crucial to ask some questions while listening to the music. With comfort in mind, the volume was chosen by the participant. In the first session, live music was played using instruments such as piano, drums, and a guitar. The song "Happy Birthday" was performed. These instruments were available for the participants to use and follow the rhythm of the song. In the music therapy sessions, the patients engaged in four different musical experiences [25]: a) improvisation: the patient composed or developed their own music using an instrument or their voice without any preparation or practice; b) re-creation: the patient played or sang a musical piece through reading the lyrics or through memorization; c) composition: the patient created a musical composition with the aid of the therapist; and d) listening: the patient reacted to the musical pieces through their own senses.

Table 2. Description of the material used throughout the intervention, the number of sessions held, the approximate length of time, and the frequency of sessions.

\begin{tabular}{lcc}
\hline Materials & No. of Sessions & Length \\
\hline Musical instruments: Piano, Guitar, Drums & Frequency & $30-60$ \\
Non-musical Materials: Photo Album, Musical Records, Bond Sheets, A3 Sheets, & 8 Sessions & Minutes Sessions per \\
Atercolors, Paintbrushes, Pencils, Erasers, Colored Markers & week for 4 weeks & \\
\hline
\end{tabular}

The interventions were carried out by the authors of this study, who hold academic degrees in clinical psychology, music therapy, and neuropsychology. The tests and musical stimulation protocol were conducted in a private space in a quiet environment, isolated from the rest of the residents. The sessions were conducted in the courtyard, patients' rooms, or the living room. Every intervention was carried out individually, and there were no group sessions due to the different musical preferences of participants.

\section{2-3- Instruments}

This research proposed a quantitative, pre-experimental, longitudinal study with the application of two tests before and after the intervention for the purpose of observing any possible changes in the autobiographical memory of the older adults diagnosed with Alzheimer's disease. The first instrument used was the Spanish adaptation of the Autobiographical Memory Test by Williams and Broadbent [26]. This test measures the type of memory evoked through the utilization of 14 keywords with positive and negative characteristics. This test evaluates the type of memory used by the patient: a) specific memories: events that happened on a specific day, time, and place; b) extended memories: a period of time that exceeds one day; c) categorical memories: events that occur repeatedly, such as holidays; d) semantic associations: associations that are not related to an event (e.g., evoking a name); and e) omissions: no response or repeating a previously mentioned event. In this research, the unit of recall was assessed based on the following scores: $0=$ omissions, $1=$ semantic association, $2=$ categorical, $3=$ extended recall, and $4=$ specific recall.

The Spanish adaptation of the Autobiographical Memory Interview by Baddeley and Kopelman [27] was utilized to evaluate the semantic and episodic components of autobiographical memory in patients with amnesia. This interview was composed of 52 questions, divided into three sections according to life milestones, such as childhood, adulthood, and recent life. The aim of the questions is to determine the state of autobiographical memory functioning, in which nine 
questions correspond to the episodic component, and the other 43 correspond to the semantic component. The type of recall achieved by the patient, the quality of the response, and their accuracy were taken into account. In the personal semantic questions, if the person did not offer any type of memory, it was scored as 0 . If the patient recalled inconclusive information, it was scored as 0.5 or 1 , depending on the information given, and if the memory was specific, it was scored as 2 points. Thus, a maximum value of 86 points and a minimum value of 0 were possible in this test. In the episodic incident questions, the scores were in the range of 0 as the minimum, and 3 as the maximum score possible. The maximum possible score for this test was 27 points, with a minimum of 0 .

\section{2-4- Procedures}

This study started by requesting authorization for the research at the university of affiliation of the authors. Approval was obtained to conduct the research at the selected foundation. The musical intervention protocol was developed, and assessment tests were made available. Letters of informed consent were signed by the legal representatives of the participants, as well as by the older adults diagnosed with Alzheimer's. Once voluntary participation was confirmed, a field observation was conducted and a first meeting with the residents was carried out, taking into account inclusion and exclusion criteria to identify the group to be worked with. Once all the necessary material was gathered to be applied in the research, the next step was the application of pre-intervention tests to assess AM over the course of one week. Once finished, the music stimulation protocol was applied twice a week, alternating the days for a total of four weeks. Once the intervention was finished, the AM post-intervention tests were applied again for one week.

\section{2-5- Data Analyses}

Descriptive statistical measurements were applied to obtain the percentages, frequencies, means, and standard deviations of the applied tests. A Cronbach's alpha analysis was performed to confirm the reliability of the Autobiographical Test pre- and post-intervention. Statistical techniques were used to compare the means between the pre- and post-test values. All data analyses were carried out using the Statistical Package for Social Studies (SPSS) version 24.

\section{3- Results}

\section{3-1- Results Reliability}

First, the analysis of Cronbach's alpha was conducted to confirm the reliability of the Autobiographical Memory Test (AMT); the value obtained in its pre-intervention measurement was $\alpha=0.80$. Subsequently, the post-intervention reliability of the AMT was analyzed, obtaining a value of $\alpha=0.89$.

\section{3-2- Comparison of Pre- and Post-test Values of the AMT}

A statistical comparison of the data obtained in both tests was conducted. Figure 1 shows the values of minimum (min.) and maximum (max.) frequency, mean (M), and standard deviation (S) for each variable in the pre-test and posttest of the AMT.

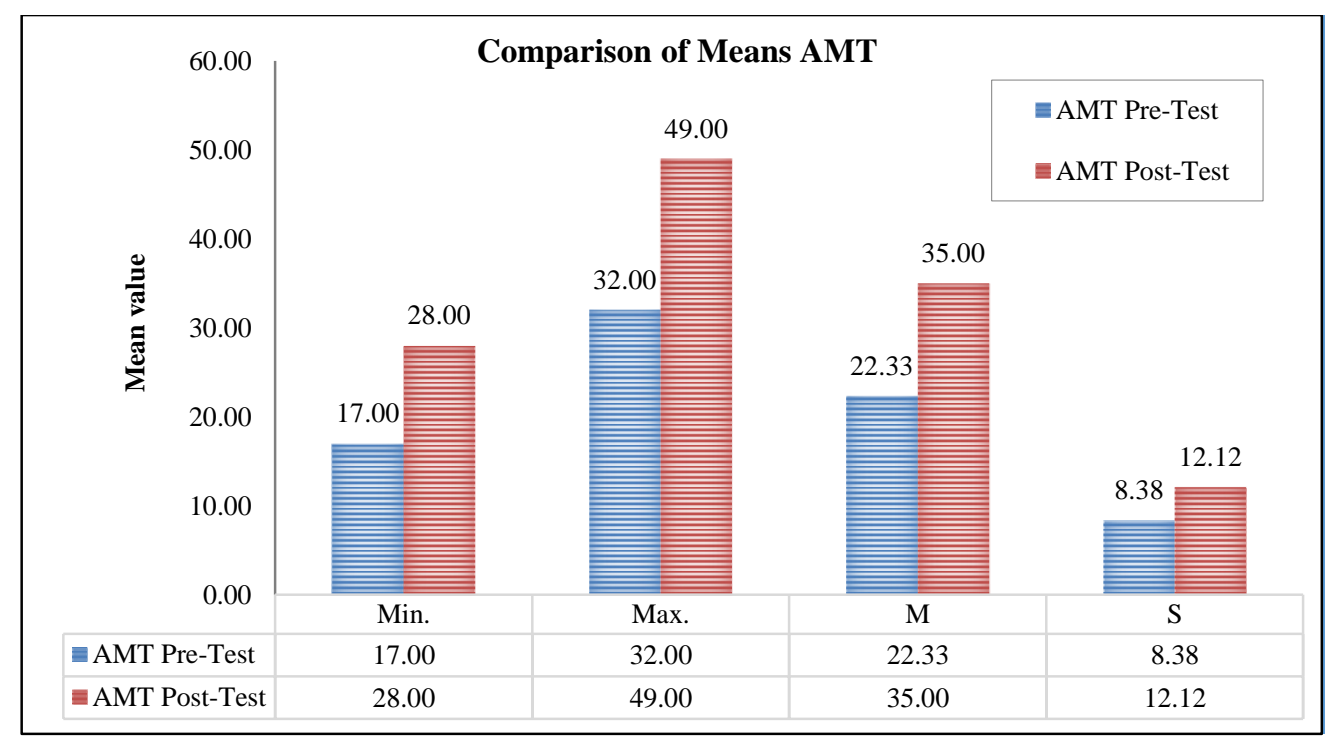

Figure 1. Statistical comparison between the pre- and post-test of the Autobiographical Memory Test.

As seen in Table 3, the post-test exceeds the pre-test with a value of $\bar{X}=-12.66$, indicating a significant difference between variables, with empirical evidence in favor of the hypothesis. 
Table 3. Paired sample test.

\begin{tabular}{ccccccccc}
\hline & \multicolumn{10}{c}{$\mathbf{9 5 \%}$ CI of the difference } \\
\hline Sample & M & S & SEM & Low & High & t & df & Sig. (bilateral) \\
\hline AMT pre-test-AMT post-test & -12.66 & 3.78 & 2.18 & -22.07 & -3.26 & -5.79 & 2.00 & 0.02 \\
\hline
\end{tabular}

\section{3-3- Comparison of Pre- and Post-tests for the AMI}

A statistical comparison of the data obtained in the semantic component of the Autobiographical Memory Interview was performed. Figure 2 shows the mean (M), standard deviation (S), and standard error mean (SEM) obtained for each variable in both the pre- and post-tests.

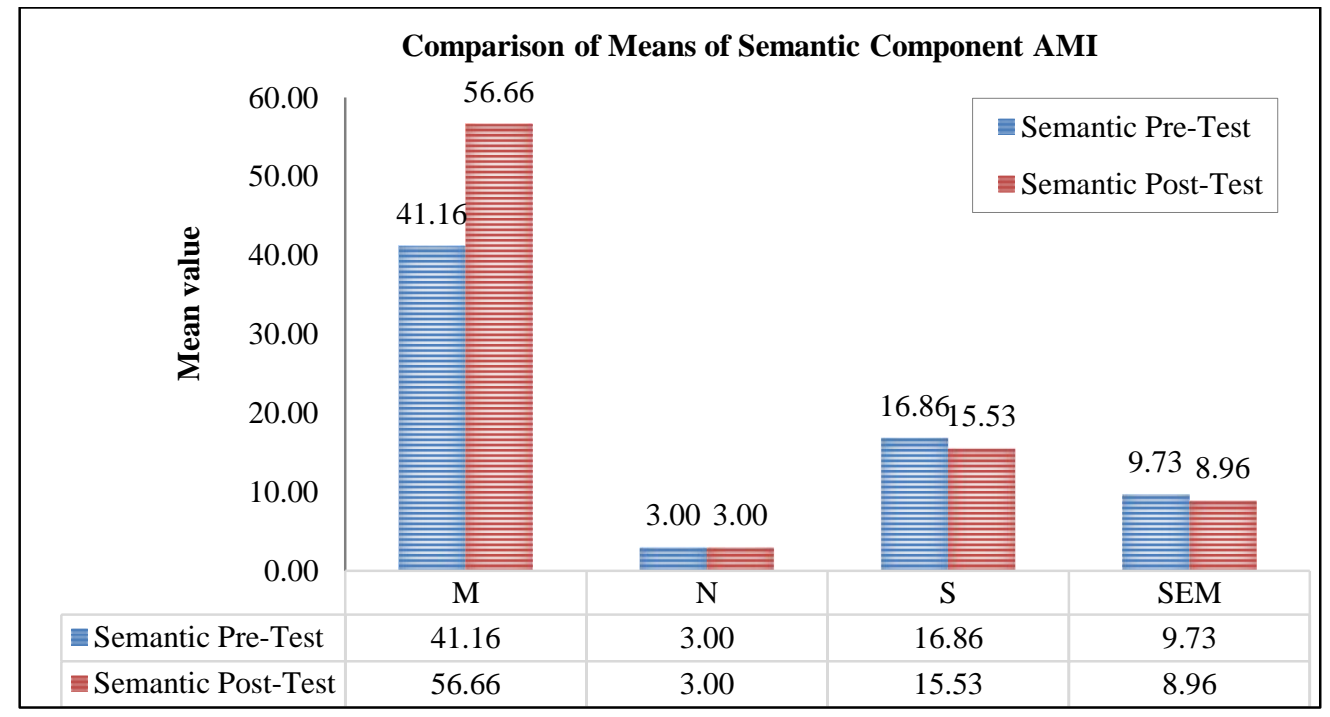

Figure 2. Statistical comparison of pre-and post-tests of the semantic component of the Autobiographical Memory Interview.

As seen in Table 4, the post-test exceeded the value of $\bar{x}=-15.50$, achieving a significant difference between variables, which contributes empirical evidence in favor of the hypothesis.

Table 4. Paired sample test.

\begin{tabular}{ccccccccc}
\hline & \multicolumn{7}{c}{$\mathbf{9 5 \%}$ CI of the difference } \\
\hline Sample & M & S & SEM & Low & High & t & df & Sig. (bilateral) \\
\hline Semantic pre-test-semantic post-test & -15.50 & 2.64 & 1.52 & -22.07 & -8.92 & -10.14 & 2.00 & 0.01 \\
\hline
\end{tabular}

A statistical comparison was performed for means of the episodic component of the Autobiographical Memory Interview. Figure 3 shows the mean (M), standard deviation (S), and SEM of each variable for both the pre- and posttests.

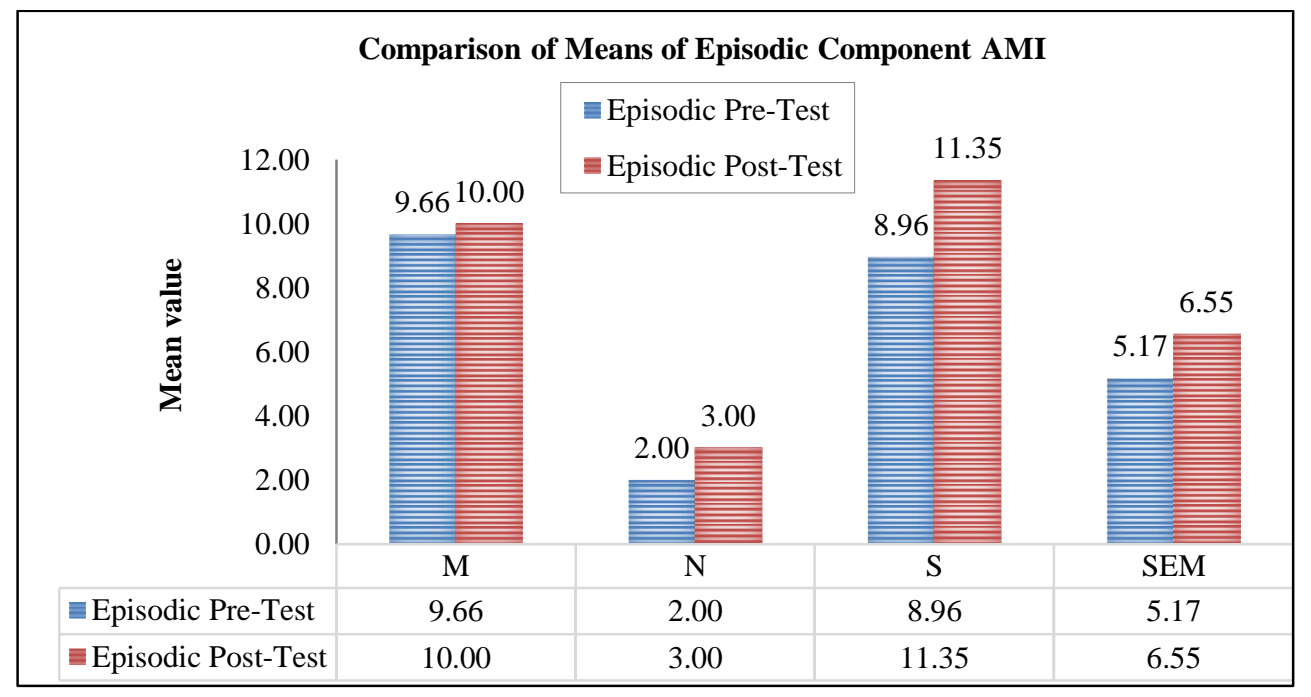

Figure 3. Statistical comparison of the episodic component of the Autobiographical Memory Interview pre- and post-tests. 
In Table 5, the post-test exceeds a value of $\bar{x}=-0.33$; thus, there is no significant difference between variables.

Table 5. Paired sample test.

\begin{tabular}{ccccccccc}
\hline & \multicolumn{8}{c}{ 95\% CI of the difference } \\
\hline Sample & M & S & SEM & Low & High & t & df & Sig. (bilateral) \\
\hline Episodic pre-test-Episodic post-test & -.33 & 3.05 & 1.76 & -7.92 & 7.25 & -.19 & 2.00 & 0.86 \\
\hline
\end{tabular}

\section{4- Discussion}

The literature about the relationship between music and dementia has demonstrated that music has the ability to positively affect symptom control in neuropsychological disorders; however, it is still a developing field [10]. Therefore, it is necessary to develop clinical trials that promote standardized protocols based on the stage of the disease, or the biopsychosocial skills that need to be worked on through music therapy [11], and that can be applied as a complementary tool. This can enable caregivers of patients diagnosed with AD to cope with symptoms of the disease, such as memory impairment, which interferes with their quality of life [28].

On this basis, this research presents a protocol of musical stimulation as a therapeutic method for the optimization of AM in older adults diagnosed with Alzheimer's disease who are in the early or middle stages. This protocol is structured on music therapy techniques and the performance of psychological exercises. The results suggest that the protocol had a positive effect on autobiographical memory and its ability to evoke memories. To arrive at this assumption, a statistical analysis of the data obtained from the application of pre- and post-intervention tests was carried out, and it was determined that in most of the post-test variables, the results had a significantly higher score, thus providing empirical evidence that music can improve the autobiographical memories of people with Alzheimer's disease.

In the AMT, the post-test showed better outcomes than the pre-test, and it was observed that the participants achieved an improvement in their capacity to evoke memories after the application of the protocol. Patients in the present research interacted in a series of stimulating musical activities that allowed their neuronal systems to establish new connections $[29,30]$, meaning that music had the ability to stimulate unique associations and activate brain areas, including the frontal, cortical, occipital, temporal, and motor zones, as well as the limbic system and cerebellum [23, 5]. Cognitive functions such as memory, can perform their optimal functioning through various brain subsystems stimulated by music therapy.

Likewise, Moreno-Morales et al. [11] reported that listening to music required integration of cognitive functions to perceive sounds, rhythms, and lyrics that require attention, which implies that brain areas are activated. In addition, through musical training, neuroplasticity is stimulated, and neuronal degeneration is reduced. Authors such as Soufineyestani, Khan, and Sufineyestani [20] suggest that singing can improve mood, reduce behavioral disturbances, optimize the functioning of cognitive abilities, and increase hormone levels and heartbeat. Playing an instrument can prevent or delay the onset of symptoms. Likewise, by actively taking part in music therapy, the ability to stay oriented in time and space improves, and raises a participant's state of consciousness about themselves and the people around them. Being passively involved in musical activities, such as listening to music, facilitates reminiscence, reinforces a sense of identity, and promotes positive reactions. Several studies on AD suggest that musical memory is preserved, even in advanced stages of the disease, especially implicit musical memory; however, these studies are not conclusive due to the lack of experimental research [12].

Another factor to consider was that the semantic component of autobiographical memory demonstrated better results after the application of the protocol. It is important to understand that older adults with AD present difficulties in verbal fluency, and their ability to express themselves is slow due to the decreasing use of nouns and word searches caused by anomie [31]. However, clinical observations suggested that there was an improvement in their ability to communicate, they were able to evoke memories with higher fluency, they participated actively in the conversations, and their pronunciation was clear to the listener. It was also evident that their capacity to name words increased, and the prolonged pauses present at the beginning due to difficulty remembering were significantly reduced.

El Haj et al. [14] stated that the use of personally meaningful music allows autobiographical memories to be evoked with higher fluency and expressed with higher grammatical complexity [5]. Our findings with regard to the impact that music has on communication coincides with previous studies that suggest people with dementia can benefit from music, and that it can improve language skills, verbal and non-verbal expressions, uninhibited self-expression, cognitive abilities, and sociability [20]. Although most of the variables suggest an improvement in the performance of AM in older adults with Alzheimer's disease, in the episodic component of the Autobiographical Memory Interview, no significant difference was observed. The results remained almost the same as in the pre-test. It is possible that this may be related to the directive structure of this test, since when participants were asked to evoke a memory about a specific topic, they had difficulties in following this direction and manifested fatigue and low motivation. Another factor may be that the number of sessions was not sufficient to demonstrate a significant improvement. 
After the application of the protocol, when asked to freely evoke a memory while in a stimulating environment, the participants were able to recall memories of different levels of specificity in all sessions. They were also able to recover information about specific events knowledge in the autobiographical memory. This type of memory, as discussed by Conway and Pleydell-Pearce [8], has a high degree of specificity and is considered a vivid memory, in which memories of life periods and general events are involved in retrieving the stored information. This could be due to the use of preferred music for each adult with $\mathrm{AD}$, since every person has a unique musical identity linked to previous experiences and with the ability to provoke emotions. Music generates motivation toward the activities, and helps people identify themselves with a song and internalize it, which makes memory evocation possible [23, 34]. In addition, a favorable factor of familiar music is that favorite songs, having been listened to frequently, strengthen the link between the stimulus and the memory associated with it [32], which in turn activates the reward centers of the limbic system, allowing easier retrieval of information [5].

It was evident during the research that Alzheimer's patients, regardless of the progression of their disease, were capable of easily remembering the lyrics of a song while singing, in contrast to their verbal expression during a conversation. Fraile et al. [18] reported that AD patients were able to learn new information, and a study by Ratohery et al. [33] suggested that this could be explained by the preservation of musical processing in AD. This is in contrast to usual language processing deficits, as sung texts are easier to remember than spoken ones. The act of narrating together with a musical activity allows older adults with Alzheimer's to remember events from their past in a more fluid way, and allows them to remain active, reinforce their own identity, and feel part of their environment. In addition, music makes it possible to elevate their mood, reduce symptoms of depression, and alleviate their agitation while allowing evocation of autobiographical memories [5]. Several authors have emphasized the ability of people with dementia to enjoy music and respond to it, even when verbal communication is not possible [11].

Due to the evocative power of music, it can play a fundamental role in helping adults with Alzheimer's reinforce their identity and ability to experience emotions since it allows them to reexamine their past, present, and future [34]. In this way, music therapy can help patients remember the roles they play in their lives and improve their relationships with those closest to them [35]. A study carried out by Otera et al. [34] determined that music has the ability to function as a common language between the patient and their family member, overcoming communication barriers, allowing for a stronger bond and union, and maintaining relationships between caregivers and patients. By allowing greater clarity for participants and improving their ability to communicate and establish relationships, it is possible to improve relationships with family, friends, and caregivers [21].

There were a number of limitations in this research. There was some difficulty registering the musical preferences of the participants, since some relatives lacked this knowledge. It was difficult for the older adults to remember the names of singers or songs. The space where the protocol took place could be improved in our future research, for example, by increasing the exclusive sonority of the musical stimuli, which would allow the older adults to maintain their focus. Working with Alzheimer's patients can involve difficulties because symptoms of the disease could bring behavioral and emotional changes. In addition, the disease is progressive and continuous, and further adversities are experienced along the way.

\section{5- Conclusion}

Current findings indicate that a protocol of musical stimulation can be used as a therapeutic tool to enable the optimization of autobiographical memory in people with Alzheimer's. This study showed that the protocol was a safe and well-tolerated intervention that can be used with patients in the initial and moderate stages of the disease; however, more research is necessary to determine its effect in advanced stages. The musical stimulation protocol is suggested as an effective technique for professionals who work with people suffering from dementia and their relatives, since it is not only a new tool to stimulate the memory of patients, but it can also be used as a method to establish better communication and relationships.

\section{6- Declarations}

\section{6-1-Author Contributions}

A.P. and C.R. contributed to the conceptualization, investigated the data, carried out the formal analysis and project administration, wrote the original draft, and reviewed and edited the manuscript. P.A. and J.C. investigated the data, carried out the formal analysis, and reviewed and edited the manuscript.

\section{6-2-Data Availability Statement}

The data presented in this study are available on request from the corresponding author.

\section{6-3-Funding}

The authors received no financial support for the research, authorship, and/or publication of this article. 


\section{6-4- Conflicts of Interest}

The authors declare that there is no conflict of interests regarding the publication of this manuscript. In addition, the ethical issues, including plagiarism, informed consent, misconduct, data fabrication and/or falsification, double publication and/or submission, and redundancies have been completely observed by the authors.

\section{7- References}

[1] Alzheimer's Disease International (ADI). "Dementia Statistics." (2020). Available online: https://www.alz.co.uk/research/statistics (accessed on April 2021).

[2] Organización Mundial de la Salud (OMS). "Demencia.” (2019). Available online: https://www.who.int/es/news-room/factsheets/detail/dementia (accessed on April 2021).

[3] Pinto, Bismarck, Scherezada Exeni, and Karina Peñaloza. "Factores biopsicosociales en la demencia tipo Alzheimer." Ajayu Órgano de Difusión Científica del Departamento de Psicología UCBSP 5, no. 2 (2007): 111-149.

[4] Schneider, Felicitas, Alan Horowitz, Klaus-Peter Lesch, and Thomas Dandekar. "Delaying Memory Decline: Different Options and Emerging Solutions.” Translational Psychiatry 10, no. 1 (January 21, 2020). doi:10.1038/s41398-020-0697-x.

[5] Brancatisano, Olivia, Amee Baird, and William Forde Thompson. "Why Is Music Therapeutic for Neurological Disorders? The Therapeutic Music Capacities Model.” Neuroscience \& Biobehavioral Reviews 112 (May 2020): 600-615. doi:10.1016/j.neubiorev.2020.02.008.

[6] Greene, John D.W., John R. Hodges, and Alan D. Baddeley. "Autobiographical Memory and Executive Function in Early Dementia of Alzheimer Type.” Neuropsychologia 33, no. 12 (December 1995): 1647-1670. doi:10.1016/0028-3932(95)000461 .

[7] Serra, Laura, Marco Bozzali, Lucia Fadda, Maria Stefania De Simone, Michela Bruschini, Roberta Perri, Carlo Caltagirone, and Giovanni A. Carlesimo. "The role of hippocampus in the retrieval of autobiographical memories in patients with amnestic Mild Cognitive Impairment due to Alzheimer's disease." Journal of neuropsychology 14, no. 1 (2020): 46-68. doi: 10.1111/jnp.12174.

[8] Conway, Martin A., and Christopher W. Pleydell-Pearce. "The Construction of Autobiographical Memories in the Self-Memory System.” Psychological Review 107, no. 2 (2000): 261-288. doi:10.1037/0033-295x.107.2.261.

[9] El Haj, Mohamad, Abdelhalim Boudoukha, Ahmed A. Moustafa, Pascal Antoine, Philippe Allain, and Karim Gallouj. “'La Vie En Rose': A Positive Shift of Autobiographical Memory in Alzheimer's Disease.” Archives of Gerontology and Geriatrics 86 (January 2020): 103953. doi:10.1016/j.archger.2019.103953.

[10] Dowson, Becky, Orii McDermott, and Justine Schneider. "What Indicators Have Been Used to Evaluate the Impact of Music on the Health and Wellbeing of People with Dementia? A Review Using Meta-Narrative Methods." Maturitas 127 (September 2019): 26-34. doi:10.1016/j.maturitas.2019.06.001.

[11] Dowson, Becky, Orii McDermott, and Justine Schneider. "What Indicators Have Been Used to Evaluate the Impact of Music on the Health and Wellbeing of People with Dementia? A Review Using Meta-Narrative Methods." Maturitas 127 (September 2019): 26-34. doi:10.1016/j.maturitas.2019.06.001.

[12] Jacobsen, Jörn-Henrik, Johannes Stelzer, Thomas Hans Fritz, Gael Chételat, Renaud La Joie, and Robert Turner. "Why Musical Memory Can Be Preserved in Advanced Alzheimer's Disease." Brain 138, no. 8 (June 3, 2015): $2438-2450$. doi:10.1093/brain/awv135.

[13] Baird, Amee, and Séverine Samson. "Music and Dementia." Music, Neurology, and Neuroscience: Evolution, the Musical Brain, Medical Conditions, and Therapies (2015): 207-235. doi:10.1016/bs.pbr.2014.11.028.

[14] El Haj, Mohamad, Luciano Fasotti, and Philippe Allain. "The Involuntary Nature of Music-Evoked Autobiographical Memories in Alzheimer's Disease.” Consciousness and Cognition 21, no. 1 (March 2012): 238-246. doi:10.1016/j.concog.2011.12.005.

[15] Prickett, Carol A., and Randall S. Moore. "The use of music to aid memory of Alzheimer's patients." Journal of Music Therapy 28, no. 2 (1991): 101-110. doi:10.1093/jmt/28.2.101.

[16] Janata, Petr, Stefan T. Tomic, and Sonja K. Rakowski. "Characterisation of Music-Evoked Autobiographical Memories." Memory 15, no. 8 (November 2007): 845-860. doi:10.1080/09658210701734593.

[17] Baird, Amee, Olivia Brancatisano, Rebecca Gelding, and William Forde Thompson. "Music Evoked Autobiographical Memories in People with Behavioural Variant Frontotemporal Dementia.” Memory 28, no. 3 (January 20, 2020): 323 -336. doi:10.1080/09658211.2020.1713379.

[18] Fraile, Elodie, Daisy Bernon, Isabelle Rouch, Elodie Pongan, Barbara Tillmann, and Yohana Lévêque. "The Effect of Learning an Individualized Song on Autobiographical Memory Recall in Individuals with Alzheimer's Disease: A Pilot Study.” Journal of Clinical and Experimental Neuropsychology 41, no. 7 (May 30, 2019): 760-768. doi:10.1080/13803395.2019.1617837. 
[19] Cuddy, Lola L., Ritu Sikka, Kristen Silveira, Sean Bai, and Ashley Vanstone. "Music-Evoked Autobiographical Memories (MEAMs) in Alzheimer Disease: Evidence for a Positivity Effect." Edited by Peter Walla. Cogent Psychology 4, no. 1 (January 13, 2017): 1277578. doi:10.1080/23311908.2016.1277578.

[20] Soufineyestani, Mahsa, Arshia Khan, and Mina Sufineyestani. "Impacts of Music Intervention on Dementia: A Review Using Meta-Narrative Method and Agenda for Future Research.” Neurology International 13, no. 1 (January 1, 2021): 1-17. doi:10.3390/neurolint13010001.

[21] Gulliver, Amelia, Georgia Pike, Michelle Banfield, Alyssa R. Morse, Natasha Katruss, Harley Valerius, Melanie Pescud, Mitchell McMaster, and Susan West. "The Music Engagement Program for People with Alzheimer's Disease and Dementia: Pilot Feasibility Trial Outcomes." Evaluation and Program Planning 87 (August 2021): 101930. doi:10.1016/j.evalprogplan.2021.101930.

[22] Mercadal-Brotons M. and Martí. P. Manual de Musicoterapia en Geriatría y Demencias, Primera edición ed., España: MonsaPrayma Ediciones, (2008).

[23] De Toro, Mariano Betes. Fundamentos de musicoterapia. Gilberto Pérez del Blanco, (2000).

[24] Poch S., Compendio de Musicoterapia, Segunda ed., vol. 1, España: Herder Editorial, (2011).

[25] Bruscia K., Musicoterapia: Métodos y Prácticas, México D.F.: Editorial Pax México, (2007).

[26] Trives, Jorge Javier Ricarte, José Miguel Latorre Postigo, and Laura Ros Segura. "Diseño y análisis del funcionamiento del Test de Memoria Autobiográfica en población española." Apuntes de Psicología 31, no. 1 (2013): 3-10.

[27] López, Agustí, and Ana Isabel. "Memoria Autobiográfica y Atención. Perspectiva Cognitiva y Experimental." (2017).

[28] Deason, Rebecca G., Jessica V. Strong, Michelle J. Tat, Nicholas R. Simmons-Stern, and Andrew E. Budson. "Explicit and Implicit Memory for Music in Healthy Older Adults and Patients with Mild Alzheimer's Disease." Journal of Clinical and Experimental Neuropsychology 41, no. 2 (September 3, 2018): 158-169. doi:10.1080/13803395.2018.1510904.

[29] Cassinello, Ma Dolores Zamarrón, Luis Tárraga Mestre, and Rocío Fernández-Ballesteros. "Plasticidad cognitiva en personas con la enfermedad de Alzheimer que reciben programas de estimulación cognitiva." Psicothema 20, no. 3 (2008): $432-437$.

[30] De los Reyes Aragón, Carlos José, Juan Carlos Arango Lasprilla, Melissa Alejandra Rodríguez Díaz, María Victoria Perea Bartolomé, and Valentina Ladera Fernández. "Cognitive Rehabilitation in patients with Alzheimer's Disease." Psicología desde el Caribe 29, no. 2 (2012): 421-455.

[31] Rodrigues, Charles, Florencio Vicente Castro, and Marta Gruart. "Relación entre cognición y personalidad en enfermos con Alzheimer." International Journal of Developmental and Educational Psychology 1, no. 2 (2013): 187-196.

[32] Jakubowski, Kelly, and Anita Ghosh. "Music-Evoked Autobiographical Memories in Everyday Life." Psychology of Music 49, no. 3 (December 16, 2019): 649-666. doi:10.1177/0305735619888803.

[33] Ratovohery, Stéphie, Alexia Baudouin, Juliette Palisson, Didier Maillet, Olivier Bailon, Catherine Belin, and Pauline Narme. "Music as a Mnemonic Strategy to Mitigate Verbal Episodic Memory in Alzheimer's Disease: Does Musical Valence Matter?" Journal of Clinical and Experimental Neuropsychology 41, no. 10 (August 9, 2019): 1060-1073. doi:10.1080/13803395.2019.1650897.

[34] Otera, Masako, Seiji Saito, Hideo Kano, and Masayoshi Ichie. "Clinical Characteristics of Home-Based Music Therapy in Supporting Personhood in People with Dementia." The Arts in Psychotherapy 70 (September 2020): 101682. doi:10.1016/j.aip.2020.101682.

[35] Dassa, Ayelet, Michal Rosenbach, and Avi Gilboa. "Towards Sustainable Implementation of Music in Daily Care of People with Dementia and Their Spouses.” The Arts in Psychotherapy 71 (November 2020): 101713. doi:10.1016/j.aip.2020.101713.

[36] Slattery, Catherine F., Jennifer L. Agustus, Ross W. Paterson, Oliver McCallion, Alexander JM Foulkes, Kirsty Macpherson, Amelia M. Carton et al. "The functional neuroanatomy of musical memory in Alzheimer's disease." Cortex 115 (2019): $357-$ 370. doi:10.1016/j.cortex.2019.02.003.

[37] M. Betés de Toro, Fundamentos de musicoterapia, Madrid: Ediciones Morata, (2000).

[38] Popa, Laura-Cristina, Mihnea Costin Manea, Diana Velcea, Ion Șalapa, Mirela Manea, and Adela Magdalena Ciobanu. "Impact of Alzheimer's Dementia on Caregivers and Quality Improvement through Art and Music Therapy." Healthcare 9, no. 6 (June 9, 2021): 698. doi:10.3390/healthcare9060698. 